OPEN ACCESS

Edited by:

Fan Feng,

The 302th Hospital of PLA, China

Reviewed by:

Yingshi Zhang,

Shenyang Pharmaceutical University,

China

Shuang Cao,

Wuhan Institute of Technology, China

*Correspondence:

Xiu-hua Zhou

cmu4h_zxh@126.com

Jun-feng Hao

ygzhjf85@gmail.com

Specialty section:

This article was submitted to Molecular and Cellular Oncology,

a section of the journal

Frontiers in Oncology

Received: 16 October 2021 Accepted: 01 November 2021 Published: 26 November 2021

Citation:

Zou X-z, Hao J-f and Zhou X-h (2021) Inhibition of SREBP-1 Activation by a

Novel Small-Molecule Inhibitor

Enhances the Sensitivity of

Hepatocellular Carcinoma Tissue to

Radiofrequency Ablation.

Front. Oncol. 11:796152.

doi: 10.3389/fonc.2021.796152

\section{Inhibition of SREBP-1 Activation by a Novel Small-Molecule Inhibitor Enhances the Sensitivity of Hepatocellular Carcinoma Tissue to Radiofrequency Ablation}

\author{
Xiao-zheng Zou ${ }^{1}$, Jun-feng $\mathrm{Hao}^{2 *}$ and Xiu-hua Zhou ${ }^{1 *}$ \\ ${ }^{1}$ Department of Critical Care Medicine, The Fourth Affiliated Hospital of China Medical University, Shenyang City, China, \\ 2 Department of Nephrology, Affiliated Hospital of Guangdong Medical University/Institute of Nephrology and Zhanjiang Key \\ Laboratory of Prevention and Management of Chronic Kidney Disease, Guangdong Medical University, Zhanjiang City, China
}

Radiofrequency ablation (RFA) is an important strategy for treatment of advanced hepatocellular carcinoma (HCC). However, the prognostic indicators of RFA therapy are not known, and there are few strategies for RFA sensitization. The transcription factor sterol regulatory element binding protein 1 (SREBP)-1 regulates fatty-acid synthesis but also promotes the proliferation or metastasis of HCC cells. Here, the clinical importance of SREBP-1 and potential application of knockdown of SREBP-1 expression in RFA of advanced HCC was elucidated. In patients with advanced HCC receiving RFA, a high level of endogenous SREBP-1 expression correlated to poor survival. Inhibition of SREBP-1 activation using a novel small-molecule inhibitor, SI-1, not only inhibited the aerobic glycolysis of HCC cells, it also enhanced the antitumor effects of RFA on xenograft tumors. Overall, our results: (i) revealed the correlation between SREBP-1 and HCC severity; (ii) indicated that inhibition of SREBP-1 activation could be a promising approach for treatment of advanced HCC.

Keywords: hepatocellular carcinoma, sterol regulatory element binding protein-1, radiofrequency ablation, aerobic glycolysis, small-molecule inhibitor, RFA sensitization

\section{INTRODUCTION}

Radiofrequency ablation (RFA) is an important local therapeutic strategy for advanced hepatocellular carcinoma (HCC) (1-3). For patients with advanced HCC who are not suitable for resection, RFA can damage HCC tissue accurately and minimize damage to healthy liver tissue (4-6). RFA is considered to have several advantages, but its application can pose two major problems. First, incomplete RFA can change the characteristics of HCC tissue (e.g., induce epithelial-mesenchymal transition (EMT) of HCC tissue) and induce the recurrence and metastasis of HCC $(7,8)$. Second, the prognosis of HCC patients after RFA is not known (9-11). Hence, research on RFA against HCC is important.

A very high uptake of glucose mediates the aberrant metabolism of HCC cells $(12,13)$. This feature participates in regulation of the physical processes HCC cells, including proliferation, 
metastasis, EMT, or the resistance of HCC cells to antitumor therapies (14-16). Therefore, aberrant glucose metabolism in HCC cells could be a useful target to enhance the sensitivity of HCC to antitumor therapies.

Increasing evidence has revealed that lipid metabolism plays an important part in the high capability of HCC cells to uptake glucose (17-19). Almost $60 \%$ of the glucose taken up by HCC cells is used for the synthesis of fatty acids (17-19). Sterol regulatory element binding protein (SREBP)-1 is the most important transcription factor in lipid metabolism (20-22). In HCC cells, SREBP-1 mediates the transcription of genes related to the syntheses of fatty acids and triglycerides (17-19). Inhibition of activation of SREBP-1 via small-molecule inhibitors or small interfering (si)RNAs of SREBP-1 not only reduces the syntheses of fatty acids and triglycerides, it also inhibits glucose uptake $(23,24)$. In the present work, the results indicated that SREBP-1 is a promising target for RFA treatment. Inhibiting of SREBP-1 via its small molecular inhibitor SI-1 (SREBP-1 inhibitor) enhanced the sensitivity of HCC cells to RFA. This study not only expands our understanding of SREBP1 , but also provides new enlightenment for RFA treatment of HCC.

\section{MATERIALS AND METHODS}

\section{Clinical Samples and Cell Lines}

Eighty-one patients with advanced HCC who underwent RFA were included in the present work. The protein samples extracted from these clinical specimens were provided by Professor Hui Xie (Beijing $302^{\text {nd }}$ Hospital, Beijing, China), as described previously (25). These tissue specimens have been prepared as samples for SDS-PAGE. The baseline information of patients were shown as Supplemental Table 1. The actual situation is: the sample used for western blot detection, the character is the sample extracted by SDS-PAGE loading buffer (Use PCR tubes for aliquoting), stored at -80 degrees; it is frozen and mailed by dry ice preservation and ultra-low temperature.

For cell lines, L-02 (hepatic non-tumor cell line) and HCC cells lines were gifts from Prof. and Dr. Fan Yin in the Department of Oncology, The Second Medical Center \& National Clinical Research Center of Geriatric Disease, Chinese PLA General Hospital, Beijing, China and employed as described in the previous publication (26). They were cultured in Dulbecco's modified Eagle's medium containing 10\% fetal bovine serum at $37^{\circ} \mathrm{C}$ in an atmosphere of $5 \% \mathrm{CO}_{2}$.

In the presence work, all studies do not involve clinical trials and do not directly use patient-sourced materials. Possible human related may include some biochemical reagents and cell lines, which have been approved by the Fourth Affiliated Hospital of China Medical University.

\section{Western Blotting and Survival Analyses}

SREBP-1 expression in clinical specimens was measured by western blotting. The expression level of SREBP-1 was examined in the total protein samples extracted from the clinical specimens. The antibodies used against SREBP-1 and methods of western blotting were as described in our previous publication. SREBP-1 expression was measured by quantitative analysis of western blots via images J $(27,28)$. Patients were divided into a SREBP-1 high-level group or SREBP-1 low-level group according to the median value of SREBP-1. Various parameters associated with SREBP-1 expression were assessed: time to disease progression (TTP) post-RFA; overall survival (OS); clinical efficacy response (CER)/overall response rate [i.e., complete response $(\mathrm{CR})+$ partial response $(\mathrm{PR})]$; disease-control rate (DCR) [i.e., $\mathrm{CR}+\mathrm{PR}+$ stable disease $(\mathrm{SD})$ ] $(29,30)$.

\section{Small-Molecule Inhibitor of SREBP-1}

A small-molecule inhibitor of SREBP-1, 1-(4-bromophenyl)-3(pyridin-3-yl)urea, was chemically synthesized $\left({ }^{1} \mathrm{H}\right.$ NMR $(400$ MHz, DMSO- $\left.d_{6}\right) \delta(\mathrm{ppm}): 8.90(\mathrm{~d}, J=29.0 \mathrm{~Hz}, 2 \mathrm{H}), 8.58(\mathrm{~d}, J=$ $2.6 \mathrm{~Hz}, 1 \mathrm{H}), 8.17$ (dd, $J=4.7,1.8 \mathrm{~Hz}, 1 \mathrm{H}), 7.98-7.87(\mathrm{~m}, 1 \mathrm{H})$, $7.43(\mathrm{~d}, J=2.1 \mathrm{~Hz}, 4 \mathrm{H}), 7.29[(\mathrm{dd}, J=8.2,4.7 \mathrm{~Hz}, 1 \mathrm{H}), \mathrm{MS} m / z$ $\left.(\mathrm{M}+\mathrm{H})^{+}: 292.41\right]$ was also gifts from Prof. and Dr. Fan Yin in the Department of Oncology, The Second Medical Center \& National Clinical Research Center of Geriatric Disease, Chinese PLA General Hospital, Beijing, China. The SREBP-1 inhibitors fatostatin (catalog number: S9785) and betulin (S4754) were purchased from Selleck Chemicals (Houston, TX, USA). The powder of SI-1, fatostatin, or betulin was prepared as described in the previous publications (31-34). HCC cells were cultured and treated with the indicated concentrations of agents, and harvested for real-time reverse transcription-quantitative polymerase chain reaction (RT-qPCR), 3-(4,5-Dimethylthiazol2-yl)-2,5-diphenyltetrazolium bromide (MTT) assay, or biochemical analyses.

\section{Subcutaneous Tumor Model and RFA}

For the animal experiments (the usage of nude mice) were reviewed and approved by the Institutional Animal Care and Use Committee (IACUC) of China Medical University. MHCC97-H cells were cultured and injected into nude mice (4-6 weeks; Si-Bei-Fu Corporation, Beijing, China) to form subcutaneous tumors $(35,36)$. The volume of each subcutaneous tumor was measured as width $\times$ width $\times$ length/ 2. When the volume of the subcutaneous tumor formed by MHCC97-H cells reached $500 \mathrm{~mm}^{3}$, nude mice underwent treatment (SI-1, RFA, or RFA + SI-1) (37).

For the RFA group, the subcutaneous tumor underwent RFA using a thyroid-ablation needle (UniBlate 700-103587 17G; RITA, Crystal Lake, IL, USA) at the indicated temperature $\left(50^{\circ} \mathrm{C}, 55^{\circ} \mathrm{C}\right.$, $60^{\circ} \mathrm{C}$, or $65^{\circ} \mathrm{C}$ ) for $2 \mathrm{~min}$. For the SI- 1 group, nude mice received SI- $1(5,2,1,0.5$, or $0.2 \mathrm{mg} / \mathrm{kg})$ via the oral route. For the RFA + SI-1 group, nude mice underwent RFA $\left(50^{\circ} \mathrm{C}\right.$ for $\left.2 \mathrm{~min}\right)$ followed by administration of SI-1 (1 mg/kg bodyweight) (37). Tumor weights were measured using a precision balance.

\section{Real-Time RT-qPCR}

MHCC97-H cells were cultured and treated with the indicated concentration $(30,10,3,1,0.03,0.01$, or $0.003 \mu \mathrm{mol} / \mathrm{L})$ of SI-1, botulin, or fatostatin. Tumor tissues were harvested for the subcutaneous tumor model $(35,36)$. The total RNA of cells or tumor tissues was extracted and reverse-transcribed into 
complimentary (c)DNA according to manufacturer (Thermo Fisher Scientific, Waltham, MA, USA) instructions and the methods described in our previous publications. cDNA samples also underwent real-time RT-qPCR according to a system from Thermo Fisher Scientific (38-40). The primers used in the qPCR were: (1) ACC, Forward Sequence, 5'TTCACTCCACCT TGTCAGCGGA-3'; Reverse Sequence 5'GTCAGAGAAGCAGCCCATCACT-3'; (2) ACLY, Forward Sequence, 5'-GCTCTGCCTA TGACAGCACCAT-3'; Reverse Sequence, 5'-GTCCGATGATGGTCACTCCCTT-3'; (3) FASN, Forward Sequence, 5-TTCTACGGCTCCACGCTCTTCC-3'; Reverse Sequence, 5'-GAAGAGTCTTC GTCAGCCAGGA-3'; (4) ACS, Forward Sequence, 5'-ATCAGGCTGCTCATG GATGACC-3'; Reverse Sequence, 5'-AGTCCAAGAGCCATC GCTTCAG-3'; (5) GLUT1, Forward Sequence, 5' TTGCAGGCTTCTCCAACTGGAC-3'; Reverse Sequence, 5'CAGAACCAGGAGCAC AGTGAAG-3'; (6) LDHA, Forward Sequence, 5'-GGATCTCCAACATGGCAGCCTT-3'; Reverse Sequence, 5'-AGACGGCTTTCTCCCT CTTGCT-3'; (7) HIF1 $\alpha$, Forward Sequence, 5'-TATGAGCCAGAAGAACT TTTAGGC-3'; Reverse Sequence, 5'CACCTCTTTTGGCAA GCATCCTG-3'; (8) EPAS-1, Forward Sequence, 5' CTGTGTCTGAGAAGAGTAACTTCC-3'; Reverse Sequence, 5'-TTGCCATAGGCTG AGGACTCCT-3'; (9) N-cadherin, Forward Sequence, 5'-CCTCCAGAGTTTACTGC CATGAC3'; Reverse Sequence, 5'-GTAGGATCTCCGCC ACTGATTC3'; (10) Vimentin, Forward Sequence, 5'-AGGCAAAGCAG GAGTCCACTGA-3'; Reverse Sequence, 5'-ATCTGGCG TTCCAGGGACTCAT-3'.

\section{Biochemical Analyses}

Assays for measurement of glycolytic activity were carried out in HCC cells and tumor tissues $(26,41-43)$. We used kits for glucose uptake (colorimetric; ab136955; Abcam, Cambridge, UK), lactate (Lactate-Glo ${ }^{\mathrm{TM}}$; Promega, Fitchburg, WI, USA), adenosine triphosphate (colorimetric/fluorometric; ab83355; Abcam), and lactate dehydrogenase (LDH; MAK066; Sigma-Aldrich, Saint Louis, MO, USA). The results are shown as heatmaps following the methods described by Zhou et al., 2020 (44).

\section{Statistical Analyses}

SPSS 9.0 (IBM, Armonk, NY, USA) was used for statistical analyses. Origin 6.0 (OriginLab, Northampton, MA, USA) was employed to calculate the half-maximal inhibitory concentration $\left(\mathrm{IC}_{50}\right)$ of agents $(45,46)$. The Student's $t$-test (single-tail) was used to compare two categorical variables. $\mathrm{P}<0.05$ was considered significant.

\section{RESULTS}

\section{A High Level of Endogenous SREBP-1 Is Associated With a Poor Outcome After RFA}

SREBP-1 expression in clinical specimens was measured to reveal the roles of this transcription factor in HCC and the effect of SREBP-1 on RFA when treating HCC. The prognosis of patients with a low SREBP-1 level (SREBP-1 low group, $n=37$ ) who received RFA was much better compared with that of patients with a high SREBP-1 level (SREBP-1 high group, $n=37)$ who received RFA: the post-RFA TTP or OS of patients with a low SREBP-1 was much longer compared with that of patients with a high level of SREBP-1 (Figure 1 and Table 1) $(\mathrm{P}<0.05)$. Moreover, patients with a low SREBP-1 level also had better CER $(\mathrm{CR}+\mathrm{PT})$ and $\mathrm{DCR}(\mathrm{CR}+\mathrm{PR}+\mathrm{SD})$ compared with those of patients with a high SREBP-1 (Table 1) $(\mathrm{P}<0.05)$. Therefore, a high level of SREBP-1 was associated with a poor prognosis of patients with advanced HCC who received RFA.

\section{SI-1 Inhibited SREBP-1 Activation in MHCC97-H Cells}

To explore the potential strategies targeting SREBP-1, a smallmolecule inhibitor of SREBP-1, SI-1, was developed (Figure 2). In MHCC97-H cells (a typical HCC cell line with a high level of endogenous SREBP-1), SI-1 could inhibit SREBP-1 activation in a dose-dependent manner: SI-1 inhibited mRNA expression of the downstream genes of SREBP-1 (ACC, ACLY, FASN and ACS) (Table 2). Moreover, SI-1 inhibited Warburg effect-related features (glucose uptake, LDH activity, increased production of lactate and adenosine triphosphate), and expression of metabolism and hypoxic stress-related genes (GLUT1, LDHA) in the dose-dependent manner. EMT is an important regulator of the resistance of HCC cells to antitumor strategies. Hence, expression of the EMT-related indicators Twist, Snail, Ncadherin, and vimentin was examined. SI-1 inhibited EMT of MHCC97-H cells in a dose-dependent manner (Table 2). $\mathrm{IC}_{50}$ for SI-1 was much lower than that of the SREBP-1 inhibitors fatostatin or betulin (Table 2), which suggested that SI-1 was a more potent inhibitor of SREBP-1 activation than fatostatin or betulin.

\section{The Optimal Condition of SI-1 or RFA on Tumors Formed by MHCC97-H Cells}

The results stated above suggested SREBP-1 to be a promising target to enhance the effects of RFA against HCC. Therefore, to explore a therapeutic strategy combining SI-1 and RFA, the optimal condition of SI-1 or RFA was examined in subcutaneous tumors formed by MHCC $97-\mathrm{H}$ cells in nude mice. RFA carried out at $65^{\circ} \mathrm{C}$ for 2 min could lower the volume of HCC tissue significantly (Figures 3A-E). The RFA conditions of $60^{\circ} \mathrm{C}$ for $2 \min$ or $55^{\circ} \mathrm{C}$ for 2 min also shrank HCC tissues (Figures 3A-E). RFA carried out at $50^{\circ} \mathrm{C}$; for $2 \mathrm{~min}$ reduced $\mathrm{HCC}$ tissues only slightly but induced EMT of HCC cells in tumor tissues: increased expression of two mesenchymal markers (N-cadherin and vimentin) suppressed expression of an epithelial marker (E-cadherin) (Figure 3F). Therefore, RFA at $50^{\circ} \mathrm{C}$ for $2 \mathrm{~min}$ was chosen as the optimal condition of RFA for the next experiment.

Oral administration of SI-1 inhibited the subcutaneous growth of MHCC97-H cells in a dose-dependent manner (Figures 4A-E). SI-1 (0.5-5 mg/kg) inhibited the subcutaneous growth of MHCC97-H cell (Figures 4A-E). SI-1 $(0.2 \mathrm{mg} / \mathrm{kg})$ could not exert antitumor activity but could significantly inhibit SREBP-1 activation (Figure 4F), the Warburg effect in HCC cells in tumor tissues (Figure 4F), or EMT (Figure 4F). Therefore, SI$1(0.2 \mathrm{mg} / \mathrm{kg})$ was chosen for the next experiment. 


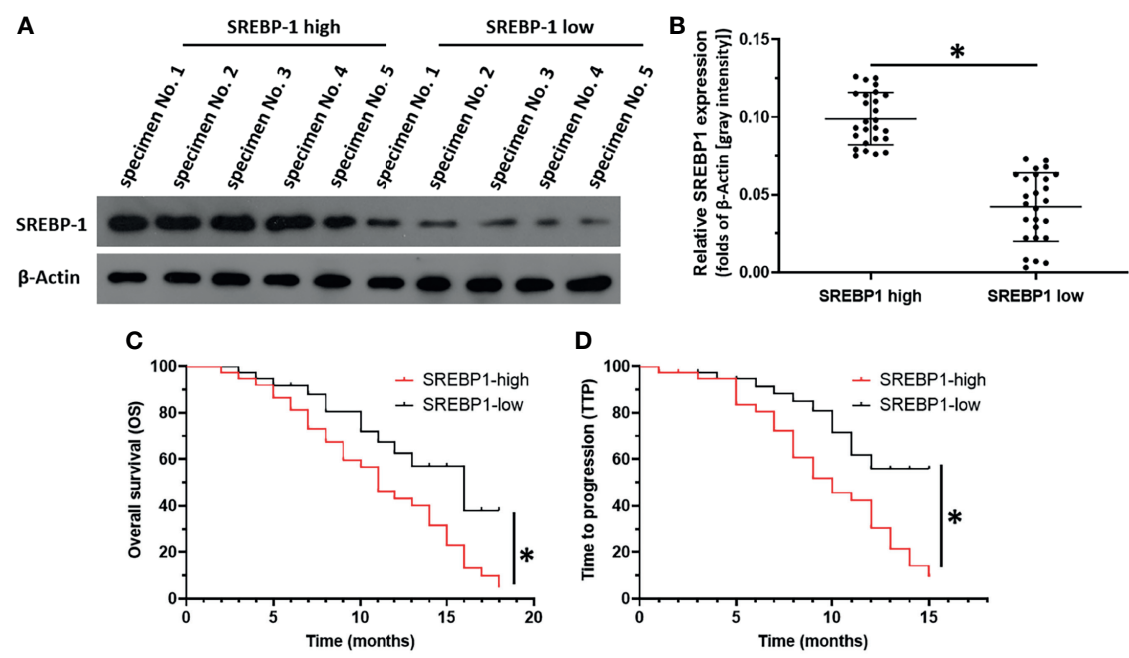

FIGURE 1 | The correlation between SREBP-1's expression with the prognosis of HCC patients post RFA. HCC tumor tissue obtained by coaxial puncture, using WB to detect the expression level of SREBP-1 in the tissue. (A) Representative images of WB results of 5 patients in the high expression group and 5 patients in the low expression group. (B) The results of WB were quantitatively analyzed by Image $\mathrm{J}$ software, and the relative expression level was calculated with the result of one of the specimens as unit 1. Divide patients into two groups based on the median relative expression level (SREBP-1 high group; SREBP-1 low group). (C, D) For SREBP-1 high group and SREBP-1 low group patients, combined with clinical data for survival analysis to determine the patient's OS and TTP. *P < 0.05 .

\section{SI-1 Enhanced the Antitumor Effect of RFA Upon HCC}

A combination of SI-1 (which represses SREBP-1 activation) and RFA on HCC was examined further. SI-1 $(0.2 \mathrm{mg} / \mathrm{kg})$ enhanced the antitumor effect of RFA ( $5^{\circ} \mathrm{C}$ for $2 \mathrm{~min}$ ) (Figure 5). Use of SI1 alone or RFA alone did not have a significant antitumor effect. The combination of SI-1 with RFA induced significant shrinkage of tumor volume (Figures 5A-E). SI-1 treatment also inhibited EMT of HCC cells in tumor tissues induced by RFA at $50^{\circ} \mathrm{C}$ for 2 min (Figure 5F). Therefore, SI-1 enhanced the antitumor effect of RFA upon HCC.

\section{DISCUSSION}

Human malignancies (especially HCC) are often characterized by anaerobic glycolysis/Warburg effect (47-49). These features aid energy generation for cellular proliferation and participate in alteration of the tumor microenvironment (49-51). Lipid metabolism is closely related to glucose metabolism (26). Hence, knockdown of SREBP-1 expression could inhibit glucose uptake or anaerobic glycolysis. Yin et al. showed that downregulation of SREBP-1 expression by betulin could enhance the sensitivity of HCC cells to molecular-targeted agents (26). Here, we revealed the novel roles of SREBP-1 in HCC regulation: SREBP-1 was related to the resistance of HCC to RFA, and knockdown of SREBP-1 expression was a promising approach to enhance the sensitivity of HCC cells to RFA. To inhibit SREBP-1 activation, a novel small-molecule inhibitor of SREBP-1, SI-1, was synthesized. We discovered that a high level of SREBP-1 in clinical specimens was correlated with a poor prognosis of HCC patients after RFA. SI-1 could inhibit SREBP-1 as well as the anaerobic glycolysis and EMT of HCC cells. Treatment with SI-1 enhanced the antitumor effect of RFA on HCC cells. Therefore, targeting SREBP-1 could be valuable for HCC treatment using RFA.

RFA is the most common therapeutic strategy for advancedstage HCC (52-54). RFA is considered to damage tumor tissues/

TABLE 1 | SREBP1 expression and clinical outcome of sorafenib treatment.

\begin{tabular}{|c|c|c|c|}
\hline & \multicolumn{2}{|c|}{ SREBP1 protein expression } & \multirow[t]{2}{*}{$P$ values } \\
\hline & High $(n=37)$ & Low $(n=37)$ & \\
\hline \multirow[t]{2}{*}{ TTP } & 10.0 & 12.0 & 0.005 \\
\hline & $7.2-12.7(\mathrm{M})$ & 10.9-13.6 (M) & \\
\hline \multirow[t]{2}{*}{ OS } & 11.0 & 16.0 & 0.024 \\
\hline & 8.7-13.3 (M) & $10.7-21.3(\mathrm{M})$ & \\
\hline Overall response rate (CR+PR) & $4(10.81 \%)$ & 17 (45.94\%) & 0.015 \\
\hline Disease control rate (CR+PR+SD) & $16(43.24 \%)$ & $28(75.67 \%)$ & 0.027 \\
\hline
\end{tabular}

TTP, time to progress; OS, overall survival; PR, partial remission; $C R$, complete remission; $S D$, stable of disease; $M$, months. 


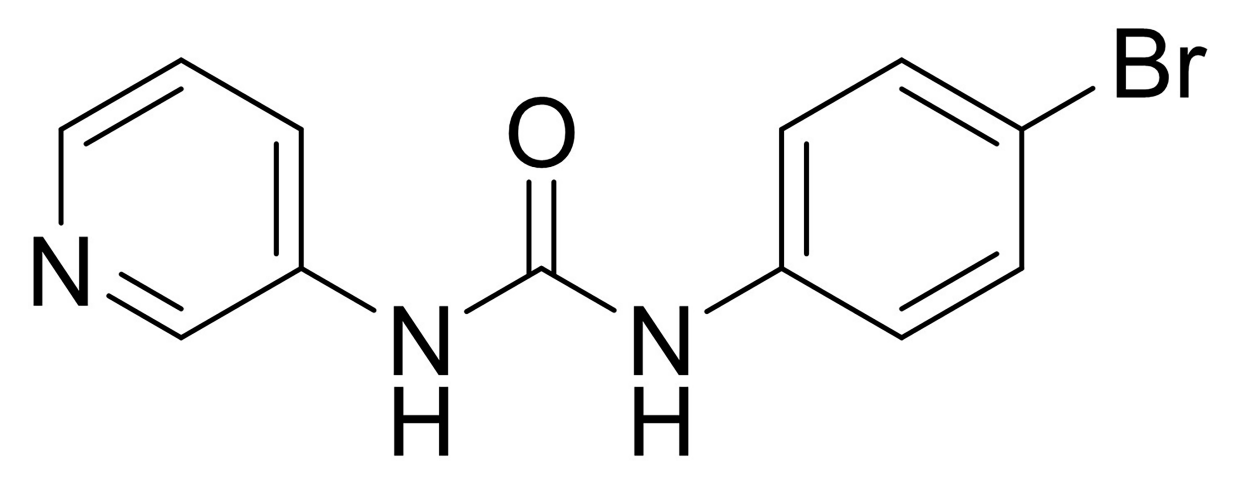

FIGURE 2 | The structure of SI-1, a novel inhibitor of SREBP-1.

lesions and elicit little damage to normal liver tissues/adjacent liver tissue (52-54). Nevertheless, RFA has three main limitations. First, research has suggested that incomplete RFA may induce cellular stress and lead to pathologic changes (e.g., EMT) $(55,56)$. Second, the temperature used for RFA cannot be increased indefinitely otherwise liver injury and incomplete RFA will occur $(55,56)$. Third, incomplete RFA may also induce EMT of HCC cells in tissue to promote HCC recurrence $(55,56)$. We showed that SREBP-1 expression was closely related to the prognosis of HCC patients treated by RFA, and that use of small-molecule inhibitors of SREBP-1 could also inhibit metabolism-related EMT. It has been demonstrated that metabolic abnormalities (e.g., anaerobic glycolysis) are closely related to drug resistance (including resistance to molecular-targeted drugs) and stress/injury response (e.g., endoplasmic reticulum stress). Our study links RFA, lipid metabolism, and sugar metabolism in cancer cells. Incomplete RFA is an important factor in RFA research/ treatment. We simulated incomplete RFA on nude mice. The RFA condition of $50^{\circ} \mathrm{C}$ for $2 \mathrm{~min}$ did not inhibit the subcutaneous growth of MHCC97-H cells in nude mice. The tumor volume shrank if RFA was supplemented with SI-1 treatment. Hence, knockdown of SREBP-1 expression may exert a sensitizing effect on RFA against HCC. Simultaneously, SI-1 may inhibit EMT in $\mathrm{HCC}$ cells induced by incomplete RFA $\left(50^{\circ} \mathrm{C}\right.$ for $\left.2 \mathrm{~min}\right)$. Hence, SI-1 could be employed to avoid the problems caused by incomplete RFA and to achieve lower RFA intensity in combination therapy to achieve more robust anti-tumor activity.

The structure of SI-1 that we synthesized was analyzed. Figure 6 shows the chemical structure core of SI-1. In this structure, R1 can be C1-C6 alkyl, C3-C10 cycloalkyl, C1-C6 alkoxy, C1-C6 alkylthio, C3-C10 cycloalkoxy, or C1-C6 alkylene groups, alkenynyl heterocycle, heterocycloalkyl, substituted heterocycloalkyl, aromatic ring, aromatic heterocycle, or benzo aromatic heterocycle, wherein the C1-C6 alkyl, aromatic ring, aromatic heterocycle, benzene, and aromatic heterocyclic ring is unsubstituted or substituted by 1, 2, 3, 4 or 5 independently substituents selected from $-\mathrm{F},-\mathrm{Cl},-\mathrm{Br},-\mathrm{I}$, nitro, hydroxyl, amino, cyano, C1-C6 alkylthio, C1-C6 alkyl, C1-C6 alkenyl, C1-C6 alkynyl, C1-C6 alkoxy, or aromatic groups. The chemical structure of SI- 1 can be modified in future studies.

It has been confirmed that SREBP-1 is an important regulator of many liver diseases $(57,58)$. On the one hand, SREBP-1 plays

TABLE 2 | The activation of SI-1 compared with the Betulin or Fatostatin.

\begin{tabular}{|c|c|c|c|}
\hline \multirow[t]{2}{*}{ Factors } & SI-1 & Betulin & Fatostatin \\
\hline & \multicolumn{3}{|c|}{ The $I C_{50}$ values $(\mu \mathrm{mol} / \mathrm{L})$} \\
\hline ACC & $0.50 \pm 0.01$ & $1.48 \pm 0.29$ & $0.98 \pm 0.15$ \\
\hline ACLY & $0.65 \pm 0.08$ & $1.27 \pm 0.44$ & $1.63 \pm 0.53$ \\
\hline FASN & $0.34 \pm 0.03$ & $1.56 \pm 0.46$ & $1.03 \pm 0.40$ \\
\hline ACS & $0.54 \pm 0.13$ & $1.08 \pm 0.20$ & $0.91 \pm 0.15$ \\
\hline GLUT1 & $0.72 \pm 0.05$ & $1.82 \pm 0.24$ & $1.53 \pm 0.78$ \\
\hline LDHA & $0.61 \pm 0.10$ & $1.64 \pm 0.62$ & $1.15 \pm 0.60$ \\
\hline $\mathrm{HIF}-1 \alpha$ & $0.88 \pm 0.25$ & $2.04 \pm 0.65$ & $1.17 \pm 0.55$ \\
\hline EPAS-1 & $0.78 \pm 0.41$ & $1.99 \pm 0.11$ & $1.33 \pm 0.27$ \\
\hline LDHA & $0.79 \pm 0.30$ & $1.64 \pm 0.33$ & $1.20 \pm 0.72$ \\
\hline EPAS-1 & $0.86 \pm 0.53$ & $2.13 \pm 0.25$ & $1.59 \pm 0.84$ \\
\hline LDHA & $0.26 \pm 0.04$ & $1.97 \pm 0.78$ & $1.35 \pm 0.78$ \\
\hline ATP & $0.31 \pm 0.02$ & $1.82 \pm 0.67$ & $0.63 \pm 0.11$ \\
\hline Lactate & $0.28 \pm 0.08$ & $1.71 \pm 0.81$ & $0.87 \pm 0.05$ \\
\hline Glucose uptake & $0.47 \pm 0.07$ & $1.28 \pm 0.37$ & $0.45 \pm 0.18$ \\
\hline $\mathrm{N}$-cadherin & $0.79 \pm 0.26$ & $1.63 \pm 0.25$ & $0.91 \pm 0.36$ \\
\hline Vimentin & $0.75 \pm 0.32$ & $2.06 \pm 0.90$ & $0.74 \pm 0.09$ \\
\hline
\end{tabular}


A

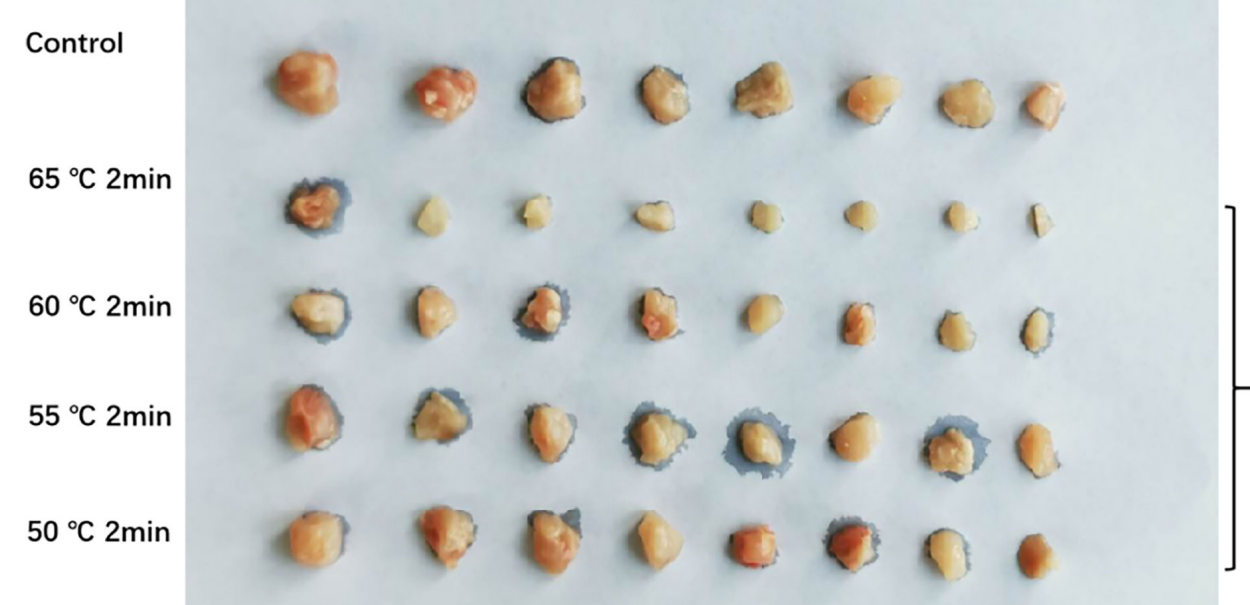

$1 \mathrm{~cm}$
D

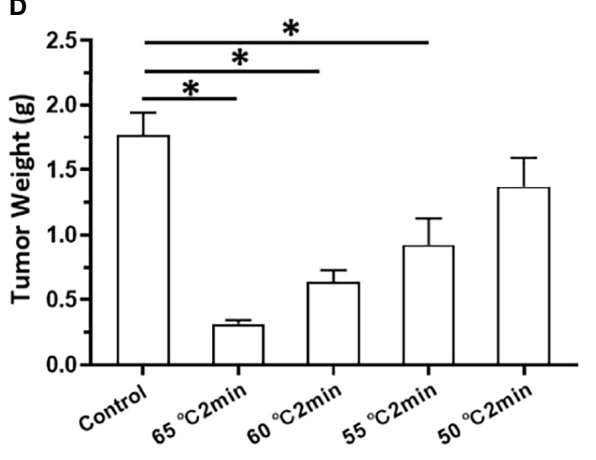

E

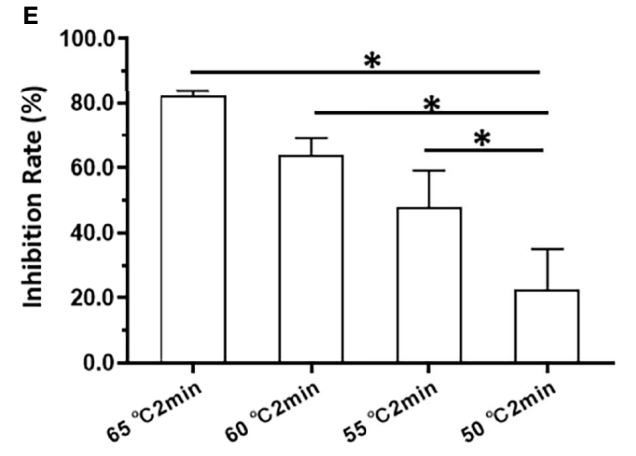
weights (D), the inhibitory rates according to the tumor weights (E), and the heat-map (F). ${ }^{*} \mathrm{P}<0.05$.

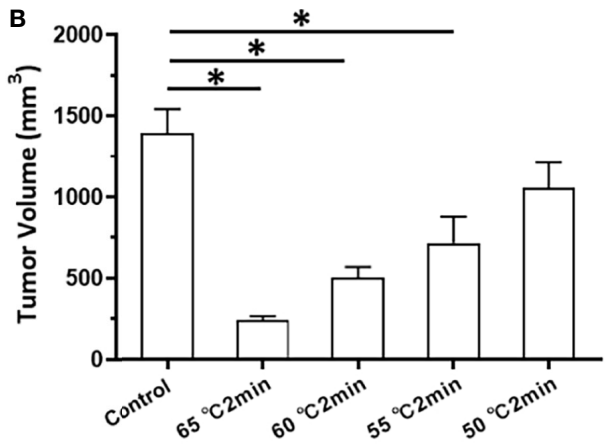

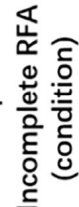
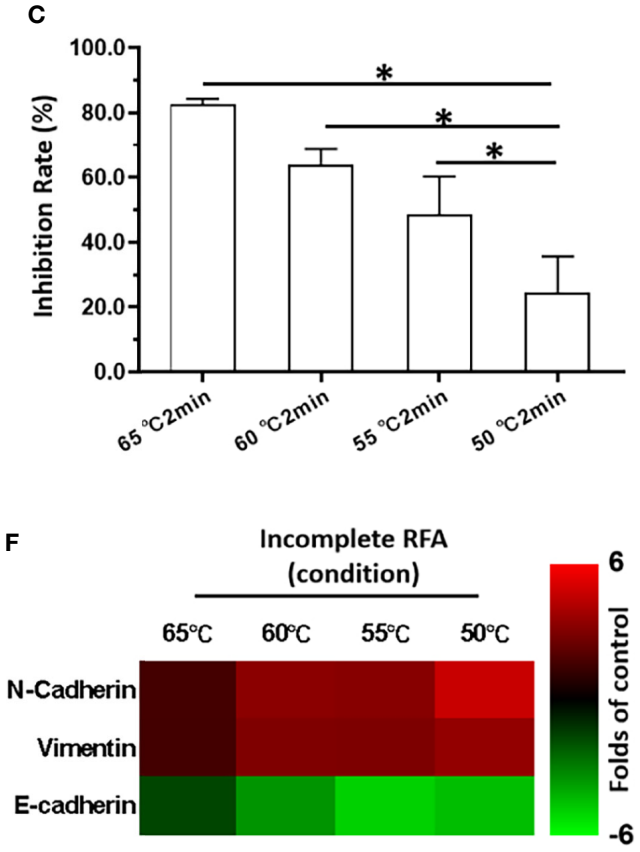

FIGURE 3 | The in vivo antitumor activation of RFA on MHCC97-H cells. The MHCC97-H cells were cultured and injected into the subcutaneous position to form the subcutaneous tumor tissues. Then, the tumor tissues were performed by the RFA $\left(65^{\circ} \mathrm{C}, 60^{\circ} \mathrm{C}, 55^{\circ} \mathrm{C}, 50^{\circ} \mathrm{C}\right)$ for $2 \mathrm{~min}$. The results were shown as images of tumors (A), the tumor volumes (B), the inhibitory rates according to the tumor volumes $(\mathbf{C})$, the tumor 
A

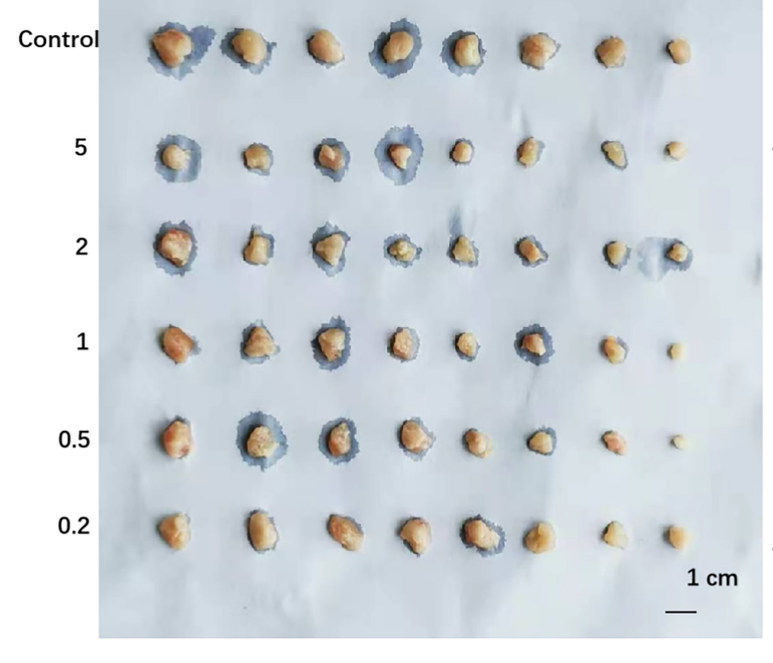

D

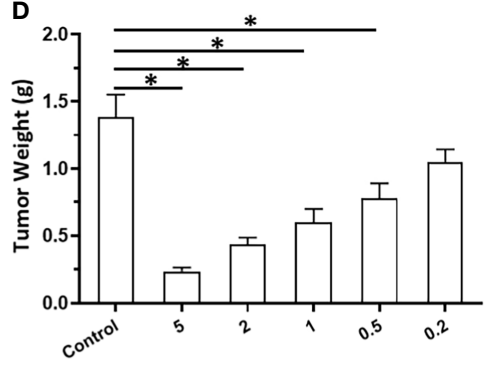

E

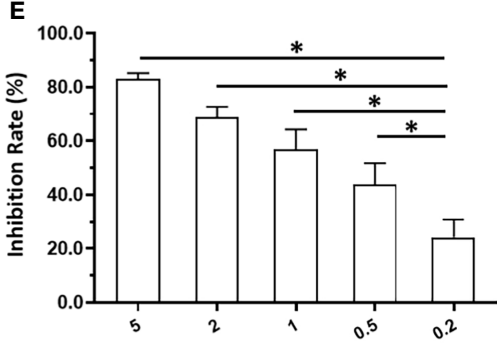

$\mathbf{F}$

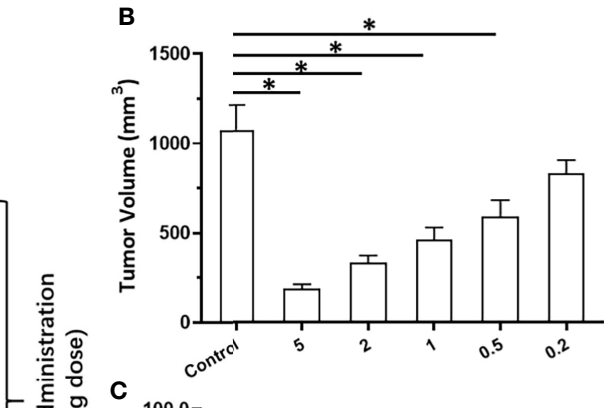

施

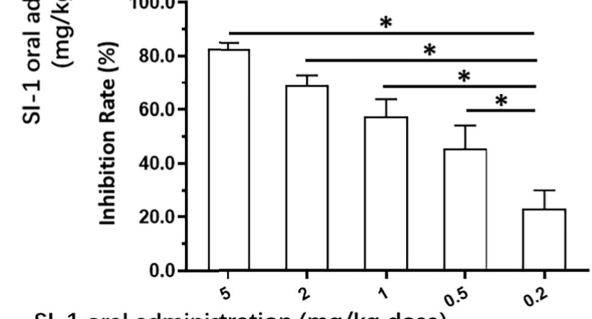

$\mathrm{SI}-1$ oral administration ( $\mathrm{mg} / \mathrm{kg}$ dose)

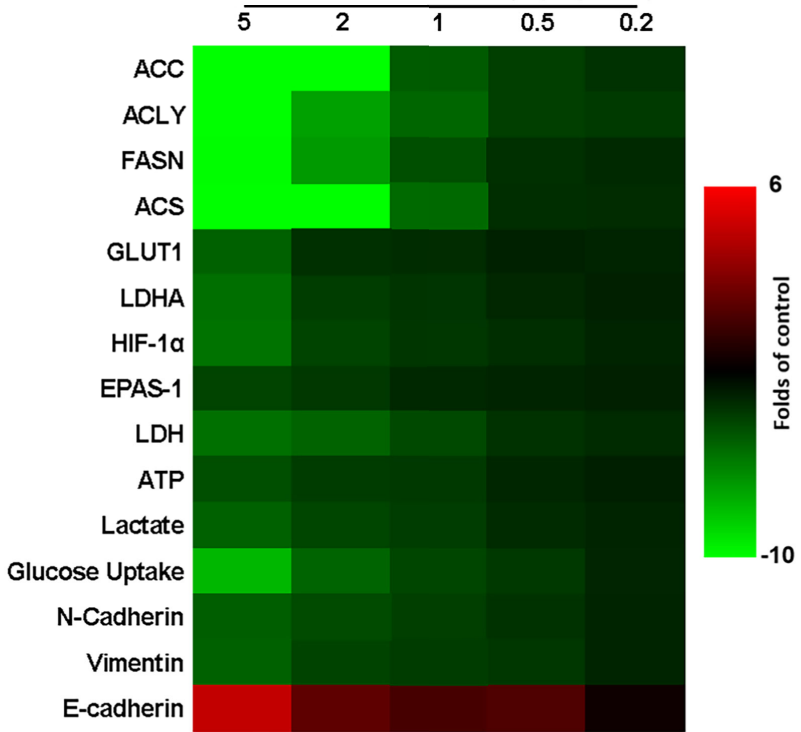

FIGURE 4 | The in vivo antitumor activation of SI-1 on MHCC97-H cells. The MHCC97-H cells were cultured and injected into the subcutaneous position to form the subcutaneous tumor tissues. Then, the mice were received the SI-1 (5mg/kg, $2 \mathrm{mg} / \mathrm{kg}, 1 \mathrm{mg} / \mathrm{kg}, 0.5 \mathrm{mg} / \mathrm{kg}, 0.2 \mathrm{mg} / \mathrm{kg}$ ) via oral administration. The results were shown as images of tumors (A), the tumor volumes (B), the inhibitory rates according to the tumor volumes (C), the tumor weights $\mathbf{( D )}$, the inhibitory rates according to the tumor weights $\mathbf{( E )}$, and the heat-map $\mathbf{( F )}$. ${ }^{*} \mathrm{P}<0.05$. 


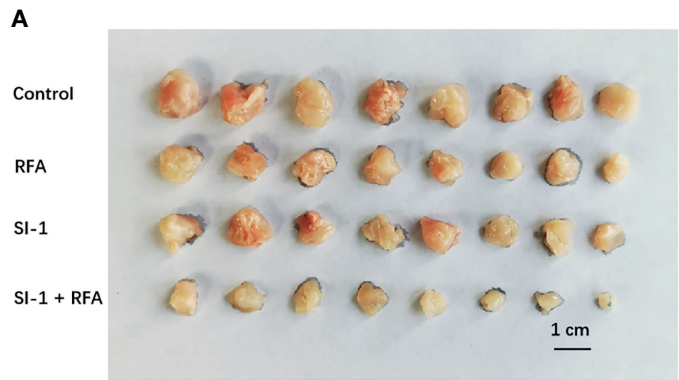

C
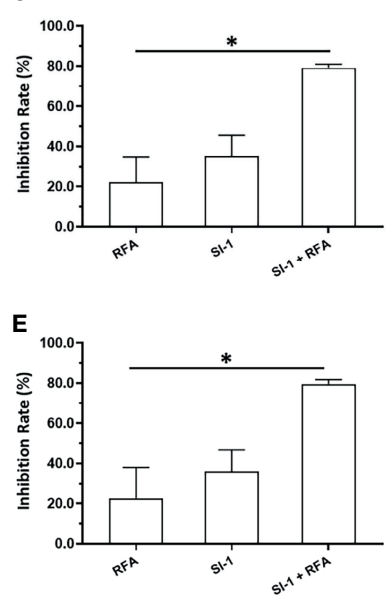

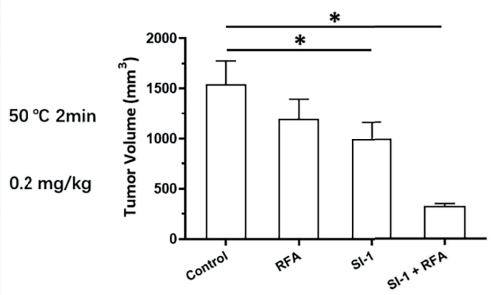

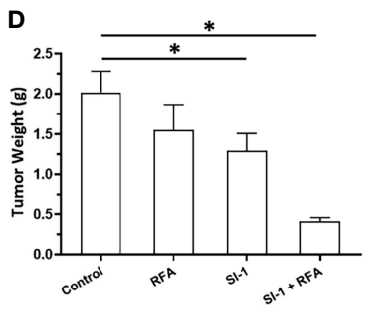

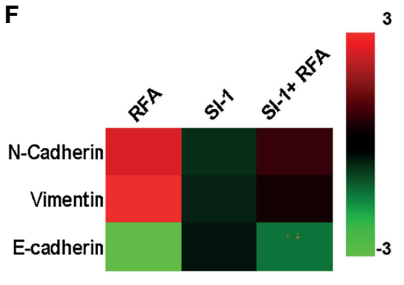

FIGURE 5 | The in vivo antitumor activation of SI-1 with RFA on MHCC97-H cells. The MHCC97-H cells were cultured and injected into the subcutaneous position to form the subcutaneous tumor tissues. Then, the mice were received the RFA $\left(50^{\circ} \mathrm{C}\right.$ for $\left.2 \mathrm{~min}\right)$ or $\mathrm{Sl}-1(0.2 \mathrm{mg} / \mathrm{kg})$ or RFA + Sl- 1 . The results were shown as images of tumors (A), the tumor volumes (B), the inhibitory rates according to the tumor volumes (C), the tumor weights (D), the inhibitory rates according to the tumor weights $(\mathbf{E})$, and the heat-map $\mathbf{( F )}$. ${ }^{*} P<0.05$.

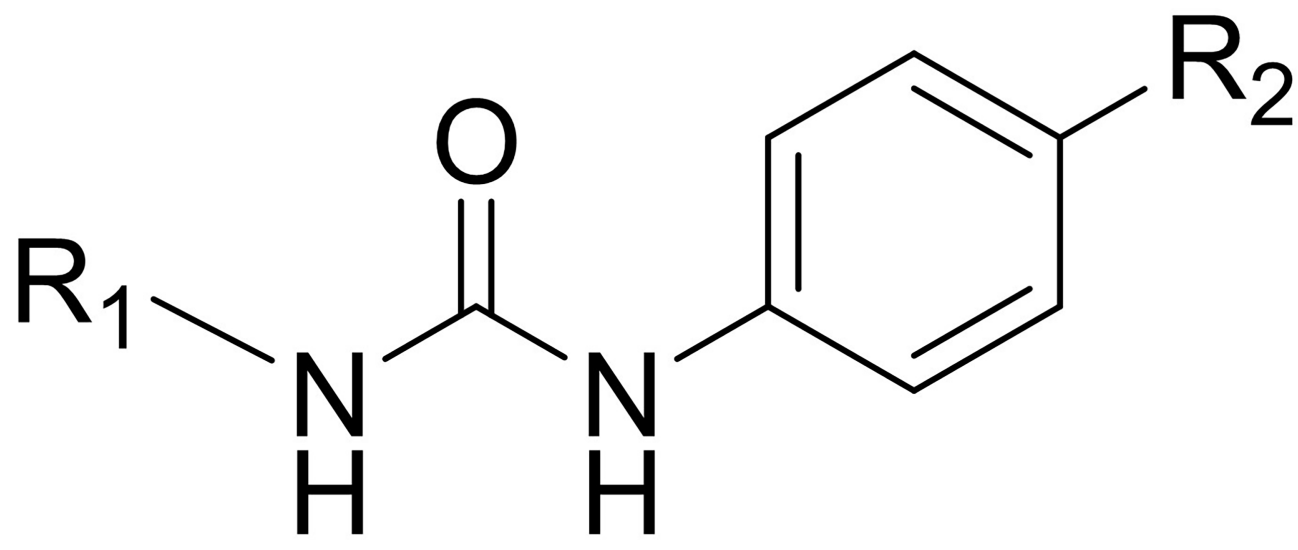

FIGURE 6 | The core structure of SI-1. R1 and R2 refers to the position of the two substituents.

an important role in metabolic diseases such as $\operatorname{NAFLD}(57,59)$. On the other hand, SREBP-1 is also clearly regarded as a positive regulator of the occurrence and progression of HCC. In HCC cells, SREBP-1 can promote the proliferation, metastasis and invasion of HCC by promoting lipid metabolism and sugar metabolism (60-63). There are many reports on the molecular mechanism of SREBP-1 $(19,64-70)$. The activity of SREBP-1 is closely related to mTOR, c-MYC, AMPK and P38, and is also regulated by CAV1 $(19,64-70)$. These related studies have shown that SREBP-1 plays an important role in the occurrence 
and progression of HCC and is an ideal intervention target for HCC treatment.

Small molecule inhibitors are an ideal mode of action for specific targets (71-74). The existing SREBP-1 small molecule inhibitors are mainly Betulin, Pseudoprotodioscin and Fatostatin (75-77). In this study, a new SREBP-1 small molecule inhibitor SI-1 was prepared, and two existing inhibitors: Betulin and Fatostatin were used. The activity of SI-1 may be better than the two existing inhibitors. For these inhibitors, the main research report is to inhibit the activity of SREBP-1 as a tool in metabolism-related research. Betulin can exert anti-tumor activity in HCC (78-80). Pseudoprotodioscin and Fatostatin have been less studied in HCC, but it has also been clearly reported in other tumor types (81-84).

\section{DATA AVAILABILITY STATEMENT}

The original contributions presented in the study are included in the article/Supplementary Material. Further inquiries can be directed to the corresponding authors.

\section{ETHICS STATEMENT}

The studies do not involve clinical trials, nor involve tissue specimens and other materials directly derived from patients. The usage of human related materials, including the protein samples for western blot or the cell lines were permitted by the Fourth Affiliated Hospital of China Medical University. The patients/participants provided their written informed consent to participate in this study. Written informed consent was

\section{REFERENCES}

1. Shi Y, Wu T, Wang T, Liu Y, Wang X, Luo J, et al. Effects of Serum From Radiofrequency Ablation Patients Receiving General Anesthesia or Local Anesthesia on Hepatocellular Carcinoma Cancer Cell Malignancy: A Prospective Randomized Controlled Trial. Front Oncol (2021) 11:686294. doi: 10.3389/fonc.2021.686294

2. Huber TC, Bochnakova T, Koethe Y, Park B, Farsad K. Percutaneous Therapies for Hepatocellular Carcinoma: Evolution of Liver Directed Therapies. J Hepatocell Carcinoma (2021) 8:1181-93. doi: 10.2147/JHC.S268300

3. Zheng X, Ren Y, Hu H, Qian K. Transarterial Chemoembolization Combined With Radiofrequency Ablation Versus Repeat Hepatectomy for Recurrent Hepatocellular Carcinoma After Curative Resection: A 10-Year Single-Center Comparative Study. Front Oncol (2021) 11:713432. doi: 10.3389/ fonc.2021.713432

4. Jiang C, Jing S, Zhou H, Li A, Qiu X, Zhu X, et al. Efficacy and Prognostic Factors of Trans-Arterial Chemoembolization Combined With Stereotactic Body Radiation Therapy for BCLC Stage B Hepatocellular Carcinoma. Front Oncol (2021) 11:640461. doi: 10.3389/fonc.2021.640461

5. Lee DH, Lee MW, Kim PN, Lee YJ, Park HS, Lee JM. Outcome of No-Touch Radiofrequency Ablation for Small Hepatocellular Carcinoma: A Multicenter Clinical Trial. Radiology (2021) 301(1):229-36. doi: 10.1148/radiol.2021210309

6. Cao G, Liu Y, Li L, Zhao X, Liu R, Liu J, et al. A Comparison of Adverse Events Among Radiofrequency Ablation, Conventional Transarterial Chemoembolization (TACE) and Drug-Eluting Bead TACE in Treating Hepatocellular Carcinoma Patients. Cancer Manag Res (2021) 13:5373-82. doi: 10.2147/CMAR.S308097 obtained from the individual(s) for the publication of any potentially identifiable images or data included in this article.

\section{AUTHOR CONTRIBUTIONS}

X-hZ, X-zZ, and J-fH: concept, design, statistics, data collection, manuscript writing, final approval. X-hZ: design, statistics, data collection. X-zZ: concept, data collection. X-zZ and J-fH: statistics, manuscript writing. X-zZ: statistics, data collection. $\mathrm{X}-\mathrm{zZ}$ and X-hZ: statistics, data collection. X-hZ: concept, design, statistics, data collection, manuscript writing, final approval. $\mathrm{X}-\mathrm{zZ}$ and J-fH Finished the revised manuscript. All authors contributed to the article and approved the submitted version.

\section{ACKNOWLEDGMENTS}

We thank Professor Xie Hui from Beijing No. 302 Hospital for the experimental materials and the guidance given in the research; we thank Professor Yin Fan from Beijing Chinese People's Liberation Army General Hospital for the cell line; thank Professor Zhou Wei from Beijing Hospital for technically help.

\section{SUPPLEMENTARY MATERIAL}

The Supplementary Material for this article can be found online at: https://www.frontiersin.org/articles/10.3389/fonc.2021.796152/ full\#supplementary-material

Supplementary Table 1 | The baseline information of patients related to this work.

7. Zhou T, Liu B, Wang Y, Wang W, Chang H, Li D, et al. Insufficient Radiofrequency Ablation Promotes Epithelial-Mesenchymal Transition Mediated by Interleukin-6/Signal Transducer and Activator of Transcription 3/Snail Pathway in the H22 Cells. J Cancer Res Ther (2020) 16(5):1112-8. doi: 10.4103/jcrt.JCRT_12_20

8. Kong J, Yao C, Ding X, Dong S, Wu S, Sun W, et al. Atpase Inhibitory Factor 1 Promotes Hepatocellular Carcinoma Progression After Insufficient Radiofrequency Ablation, and Attenuates Cell Sensitivity to Sorafenib Therapy. Front Oncol (2020) 10:1080. doi: 10.3389/fonc.2020.01080

9. Carli ALE, Afshar-Sterle S, Rai A, Fang H, O’Keefe R, Tse J, et al. Cancer Stem Cell Marker DCLK1 Reprograms Small Extracellular Vesicles Toward Migratory Phenotype in Gastric Cancer Cells. Proteomics (2021) 21(13-14): e2000098. doi: 10.1002/pmic.202000098

10. Zhou HQ, Liu MS, Deng TB, Xie PB, Wang W, Shao T, et al. The TGF- $\beta$ / Smad Pathway Inhibitor Sb431542 Enhances the Antitumor Effect of Radiofrequency Ablation on Bladder Cancer Cells. Onco Targets Ther (2019) 12:7809-7821. doi: 10.2147/OTT.S212596

11. Jindal A, Thadi A, Shailubhai K. Hepatocellular Carcinoma: Etiology and Current and Future Drugs. J Clin Exp Hepatol (2019) 9(2):221-32. doi: 10.1016/j.jceh.2019.01.004

12. Ma X, Mao Z, Zhu J, Liu H, Chen F. Lncrna PANTR1 Upregulates BCL2A1 Expression to Promote Tumorigenesis and Warburg Effect of Hepatocellular Carcinoma Through Restraining Mir-587. J Immunol Res (2021) 2021:1736819. doi: 10.1155/2021/1736819

13. Chen Y, Bei J, Liu M, Huang J, Xie L, Huang W, et al. Sublethal Heat StressInduced O-Glcnacylation Coordinates the Warburg Effect to Promote 
Hepatocellular Carcinoma Recurrence and Metastasis After Thermal Ablation. Cancer Lett (2021) 518:23-34. doi: 10.1016/j.canlet.2021.06.001

14. Gao F, Zhang X, Wang S, Zheng L, Sun Y, Wang G, et al. TSP50 Promotes the Warburg Effect and Hepatocyte Proliferation via Regulating PKM2 Acetylation. Cell Death Dis (2021) 12(6):517. doi: 10.1038/s41419-02103782-w

15. Wang S, Lv Y, Zhou Y, Ling J, Wang H, Gu D, et al. Acidic Extracellular Ph Induces Autophagy to Promote Anoikis Resistance of Hepatocellular Carcinoma Cells via Downregulation of Mir-3663-3p. J Cancer (2021) 12 (12):3418-26. doi: 10.7150/jca.51849

16. Ding L, Liang X. Ras Related GTP Binding D Promotes Aerobic Glycolysis of Hepatocellular Carcinoma. Ann Hepatol (2021) 23:100307. doi: 10.1016/ j.aohep.2021.100307

17. Luo X, Zheng E, Wei L, Zeng H, Qin H, Zhang X, et al. The Fatty Acid Receptor CD36 Promotes HCC Progression Through Activating Src/PI3K/ AKT Axis-Dependent Aerobic Glycolysis. Cell Death Dis (2021) 12(4):328. doi: 10.1038/s41419-021-03596-w

18. Hu S, Liu YM, Chen-Chen, Li LY, Zhang BY, Yang JF, et al. Microrna-708 Prevents Ethanol-Induced Hepatic Lipid Accumulation and Inflammatory Reaction via Direct Targeting ZEB1. Life Sci (2020) 258:118147. doi: 10.1016/ j.lfs. 2020.118147

19. Heo MJ, Kang SH, Kim YS, Lee JM, Yu J, Kim HR, et al. UBC12-Mediated SREBP-1 Neddylation Worsens Metastatic Tumor Prognosis. Int J Cancer (2020) 147(9):2550-63. doi: 10.1002/ijc.33113

20. Xie D, Chen C, Dong Y, You C, Wang S, Monroig Ó, et al. Regulation of LongChain Polyunsaturated Fatty Acid Biosynthesis in Teleost Fish. Prog Lipid Res (2021) 82:101095. doi: 10.1016/j.plipres.2021.101095

21. Dorotea D, Koya D, Ha H. Recent Insights Into SREBP as a Direct Mediator of Kidney Fibrosis via Lipid-Independent Pathways. Front Pharmacol (2020) 11:265. doi: 10.3389/fphar.2020.00265

22. Adlanmerini M, Carpenter BJ, Remsberg JR, Aubert Y, Peed LC, Richter HJ. Lazar MA.C Ircadian Lipid Synthesis in Brown Fat Maintains Murine Body Temperature During Chronic Cold. Proc Natl Acad Sci USA (2019) 116 (37):18691-9. doi: 10.1073/pnas.1909883116

23. Meng H, Shen M, Li J, Zhang R, Li X, Zhao L, et al. Novel SREBP1 Inhibitor Cinobufotalin Suppresses Proliferation of Hepatocellular Carcinoma by Targeting Lipogenesis. Eur J Pharmacol (2021) 906:174280. doi: 10.1016/ j.ejphar.2021.174280

24. Zhou Y, Tao J, Calvisi DF, Chen X. Role of Lipogenesis Rewiring in Hepatocellular Carcinoma. Semin Liver Dis (2021). doi: 10.1055/s-0041-1731709

25. Xie H, Yu H, Tian S, Yang X, Wang X, Wang H, et al. MEIS-1 Level in Unresectable Hepatocellular Carcinoma can Predict the Post-Treatment Outcomes of Radiofrequency Ablation. Oncotarget (2018) 9(20):15252-65. doi: 10.18632/oncotarget.24165

26. Yin F, Feng F, Wang L, Wang X, Li Z, Cao Y. SREBP-1 Inhibitor Betulin Enhances the Antitumor Effect of Sorafenib on Hepatocellular Carcinoma via Restricting Cellular Glycolytic Activity. Cell Death Dis (2019) 10(9):672. doi: 10.1038/s41419-019-1884-7

27. Jia H, Liu M, Wang X, Jiang Q, Wang S, Santhanam RK, et al. Cimigenoside Functions as a Novel $\gamma$-Secretase Inhibitor and Inhibits the Proliferation or Metastasis of Human Breast Cancer Cells by $\gamma$-Secretase/Notch Axis. Pharmacol Res (2021) 169:105686. doi: 10.1016/j.phrs.2021.105686

28. Li B, Feng F, Jia H, Jiang Q, Cao S, Wei L, et al. Rhamnetin Decelerates the Elimination and Enhances the Antitumor Effect of the Molecular-Targeting Agent Sorafenib in Hepatocellular Carcinoma Cells via the Mir-148a/PXR Axis. Food Funct (2021) 12(6):2404-17. doi: 10.1039/d0fo02270e

29. Gao XD, Qu JH, Chang XJ, Lu YY, Bai WL, Wang H, et al. Hypomethylation of Long Interspersed Nuclear Element-1 Promoter Is Associated With Poor Outcomes for Curative Resected Hepatocellular Carcinoma. Liver Int (2014) 34(1):136-46. doi: 10.1111/liv.12264

30. Yang YP, Qu JH, Chang XJ, Lu YY, Bai WL, Dong Z, et al. High Intratumoral Metastasis-Associated in Colon Cancer-1 Expression Predicts Poor Outcomes of Cryoablation Therapy for Advanced Hepatocellular Carcinoma. J Transl Med (2013) 11:41. doi: 10.1186/1479-5876-11-41

31. Zou XZ, Zhou XH, Feng YQ, Hao JF, Liang B, Jia MW. Novel Inhibitor of OCT1 Enhances the Sensitivity of Human Esophageal Squamous Cell Carcinoma Cells to Antitumor Agents. Eur J Pharmacol (2021) 907:174222. doi: 10.1016/j.ejphar.2021.174222
32. Feng YQ, Li BA, Feng F, Chen YS, Ren YX, Zhang H, et al. Novel Mtor Inhibitor Enhances the Sensitivity of Hepatocellular Carcinoma Cells to Molecular Targeting Agents. Onco Targets Ther (2020) 13:7165-76. doi: 10.2147/OTT.S244474

33. Wang Y, Liu S, Chen Q, Ren Y, Li Z, Cao S. Novel Small Molecular Inhibitor of Pit-Oct-Unc Transcription Factor 1 Suppresses Hepatocellular Carcinoma Cell Proliferation. Life Sci (2021) 277:119521. doi: 10.1016/j.lfs.2021.119521

34. Jie Y, Liu G EM, Li Y, Xu G, Guo J, Li Y, et al. Novel Small Molecule Inhibitors of the Transcription Factor ETS-1 and Their Antitumor Activity Against Hepatocellular Carcinoma. Eur J Pharmacol (2021) 906:174214. doi: 10.1016/ j.ejphar.2021.174214

35. Jiang Q, Ma Y, Han J, Chu J, Ma X, Shen L, et al. MDM2 Binding Protein Induces the Resistance of Hepatocellular Carcinoma Cells to Molecular Targeting Agents via Enhancing the Transcription Factor Activity of the Pregnane X Receptor. Front Oncol (2021) 11:715193. doi: 10.3389/fonc.2021.715193

36. Ma Y, Chai N, Jiang Q, Chang Z, Chai Y, Li X, et al. DNA Methyltransferase Mediates the Hypermethylation of the Microrna 34a Promoter and Enhances the Resistance of Patient-Derived Pancreatic Cancer Cells to Molecular Targeting Agents. Pharmacol Res (2020) 160:105071. doi: 10.1016/j.phrs.2020.105071

37. Xie H, Tian S, Yu H, Yang X, Liu J, Wang H, et al. A New Apatinib Microcrystal Formulation Enhances the Effect of Radiofrequency Ablation Treatment on Hepatocellular Carcinoma. Onco Targets Ther (2018) 11:325765. doi: 10.2147/OTT.S165000

38. Gao X, Chen H, Huang X, Li H, Liu Z, Bo X. ARQ-197 Enhances the Antitumor Effect of Sorafenib in Hepatocellular Carcinoma Cells via Decelerating Its Intracellular Clearance. Onco Targets Ther (2019) 12:162940. doi: 10.2147/OTT.S196713

39. Du Y, Shi X, Ma W, Wen P, Yu P, Wang X, et al. Phthalates Promote the Invasion of Hepatocellular Carcinoma Cells by Enhancing the Interaction Between Pregnane X Receptor and E26 Transformation Specific Sequence 1. Pharmacol Res (2021) 169:105648. doi: 10.1016/j.phrs.2021.105648

40. Wang JH, Zeng Z, Sun J, Chen Y, Gao X. A Novel Small-Molecule Antagonist Enhances the Sensitivity of Osteosarcoma to Cabozantinib In Vitro and In Vivo by Targeting DNMT-1 Correlated With Disease Severity in Human Patients. Pharmacol Res (2021) 173:105869. doi: 10.1016/j.phrs.2021.105869

41. Li H, Chen Z, Zhang Y, Yuan P, Liu J, Ding L, et al. Mir-4310 Regulates Hepatocellular Carcinoma Growth and Metastasis Through Lipid Synthesis. Cancer Lett (2021) 519:161-71. doi: 10.1016/j.canlet.2021.07.029

42. Shi Y, Zhang Y, Ran F, Liu J, Lin J, Hao X, et al. Let-7a-5p Inhibits Triple-Negative Breast Tumor Growth and Metastasis Through GLUT12-Mediated Warburg Effect. Cancer Lett (2020) 495:53-65. doi: 10.1016/j.canlet.2020.09.012

43. Li L, Liang Y, Kang L, Liu Y, Gao S, Chen S, et al. Transcriptional Regulation of the Warburg Effect in Cancer by SIX1. Cancer Cell (2018) 33(3):368-385.e7. doi: 10.1016/j.ccell.2018.01.010

44. Zhou W, Gao Y, Tong Y, Wu Q, Zhou Y, Li Y. Anlotinib Enhances the Antitumor Activity of Radiofrequency Ablation on Lung Squamous Cell Carcinoma. Pharmacol Res (2021) 164:105392. doi: 10.1016/j.phrs.2020.105392

45. Wang C, Ding S, Sun B, Shen L, Xiao L, Han Z, et al. Hsa-Mir-4271 Downregulates the Expression of Constitutive Androstane Receptor and Enhances In Vivo the Sensitivity of Non-Small Cell Lung Cancer to Gefitinib. Pharmacol Res (2020) 161:105110. doi: 10.1016/j.phrs.2020.105110

46. Yang H, Ren L, Wang Y, Bi X, Li X, Wen M, et al. FBI-1 Enhanced the Resistance of Triple-Negative Breast Cancer Cells to Chemotherapeutic Agents via the Mir-30c/PXR Axis. Cell Death Dis (2020) 11(10):851. doi: 10.1038/s41419-020-03053-0

47. Patra S, Elahi N, Armorer A, Arunachalam S, Omala J, Hamid I, et al. Mechanisms Governing Metabolic Heterogeneity in Breast Cancer and Other Tumors. Front Oncol (2021), 11:700629. doi: 10.3389/fonc.2021.700629

48. Shin E, Koo JS. Glucose Metabolism and Glucose Transporters in Breast Cancer. Front Cell Dev Biol (2021) 9:728759. doi: 10.3389/fcell.2021.728759

49. Liu C, Jin Y, Fan Z. The Mechanism of Warburg Effect-Induced Chemoresistance in Cancer. Front Oncol (2021), 11:698023. doi: 10.3389/fonc.2021.698023

50. Pérez-Herrero E, Fernández-Medarde A. The Reversed Intra- and Extracellular Ph in Tumors as a Unified Strategy to Chemotherapeutic Delivery Using Targeted Nanocarriers. Acta Pharm Sin B (2021) 11(8):2243-64. doi: 10.1016/j.apsb.2021.01.012

51. Llibre A, Grudzinska FS, O'Shea MK, Duffy D, Thickett DR, Mauro C, et al. Lactate Cross-Talk in Host-Pathogen Interactions. Biochem J (2021) 478 (17):3157-78. doi: 10.1042/BCJ20210263 
52. Feng F, Jiang Q, Jia H, Sun H, Chai Y, Li X, et al. Which Is the Best Combination of TACE and Sorafenib for Advanced Hepatocellular Carcinoma Treatment? A Systematic Review and Network Meta-Analysis. Pharmacol Res (2018) 135:89-101. doi: 10.1016/j.phrs.2018.06.021

53. Xie H, Yu H, Tian S, Yang X, Wang X, Yang Z, et al. What is the Best Combination Treatment With Transarterial Chemoembolization of Unresectable Hepatocellular Carcinoma? A Systematic Review and Network Meta-Analysis. Oncotarget (2017) 8(59):100508-23. doi: 10.18632/oncotarget.20119

54. Ochi H, Hiraoka A, Hirooka M, Koizumi Y, Amano M, Azemoto N, et al. Direct-Acting Antivirals Improve Survival and Recurrence Rates After Treatment of Hepatocellular Carcinoma Within the Milan Criteria. J Gastroenterol (2021) 56(1):90-100. doi: 10.1007/s00535-020-01747-y

55. Zhang N, Li H, Qin C, Ma D, Zhao Y, Zhu W, et al. Insufficient Radiofrequency Ablation Promotes the Metastasis of Residual Hepatocellular Carcinoma Cells via Upregulating Flotillin Proteins. J Cancer Res Clin Oncol (2019) 145(4):895907. doi: 10.1007/s00432-019-02852-z

56. Zhang $\mathrm{N}$, Wang LR, Li DD, Ma DN, Wang CH, He XG, et al. Interferon- $\alpha$ Combined With Herbal Compound "Songyou Yin" Effectively Inhibits the Increased Invasiveness and Metastasis by Insufficient Radiofrequency Ablation of Hepatocellular Carcinoma in an Animal Model. Integr Cancer Ther (2018) 17(4):1260-9. doi: 10.1177/1534735418801525

57. Fang Y, Zhan Y, Xie Y, Du S, Chen Y, Zeng Z, et al. Integration of Glucose and Cardiolipin Anabolism Confers Radiation Resistance of Hepatocellular Carcinoma. Hepatology (2021). doi: 10.1002/hep.32177

58. Zheng C, Zhu Y, Liu Q, Luo T, Xu W. Maprotiline Suppresses Cholesterol Biosynthesis and Hepatocellular Carcinoma Progression Through Direct Targeting of CRABP1. Front Pharmacol (2021) 12:689767. doi: 10.3389/ fphar.2021.689767

59. Parlati L, Régnier M, Guillou H, Postic C. New Targets for NAFLD. JHEP Rep (2021) 3(6):100346. doi: 10.1016/j.jhepr.2021.100346

60. Zhu L, Huang J, Wang Y, Yang Z, Chen X. Chemerin Causes Lipid Metabolic Imbalance and Induces Passive Lipid Accumulation in Human Hepatoma Cell Line via the Receptor GPR1. Life Sci (2021) 278:119530. doi: 10.1016/ j.lfs.2021.119530

61. Onorato A M, Fiore E, Bayo J, Casali C, Fernandez-Tomé M, Rodríguez M, et al. SPARC Inhibition Accelerates NAFLD-Associated Hepatocellular Carcinoma Development by Dysregulating Hepatic Lipid Metabolism. Liver Int (2021) 41(7):1677-93. doi: 10.1111/liv.14857

62. Xu GL, Ni CF, Liang HS, Xu YH, Wang WS, Shen J, et al. Upregulation of PDL1 Expression Promotes Epithelial-to-Mesenchymal Transition in SorafenibResistant Hepatocellular Carcinoma Cells. Gastroenterol Rep (Oxf) (2020) 8 (5):390-8. doi: 10.1093/gastro/goaa049

63. Yu X, Lin Q, Wu Z, Zhang Y, Wang T, Zhao S, et al. ZHX2 Inhibits SREBP1cMediated De Novo Lipogenesis in Hepatocellular Carcinoma via MiR-24-3p. J Pathol (2020) 252(4):358-70. doi: 10.1002/path.5530

64. Zhao M, Bu Y, Feng J, Zhang H, Chen Y, Yang G, et al. SPIN1 Triggers Abnormal Lipid Metabolism and Enhances Tumor Growth in Liver Cancer. Cancer Lett (2020) 470:54-63. doi: 10.1016/j.canlet.2019.11.032

65. Yang PM, Hong YH, Hsu KC, Liu TP. P38alpha/S1P/SREBP2 Activation by the SAM-Competitive EZH2 Inhibitor GSK343 Limits Its Anticancer Activity But Creates a Druggable Vulnerability in Hepatocellular Carcinoma. Am J Cancer Res (2019) 9(10):2120-39.

66. Triki M, Rinaldi G, Planque M, Broekaert D, Winkelkotte AM, Maier CR, et al. Mtor Signaling and SREBP Activity Increase FADS2 Expression and can Activate Sapienate Biosynthesis. Cell Rep (2020) 31(12):107806. doi: 10.1016/ j.celrep.2020.107806

67. Zhao Y, Li M, Yao X, Fei Y, Lin Z, Li Z, et al. HCAR1/MCT1 Regulates Tumor Ferroptosis Through the Lactate-Mediated AMPK-SCD1 Activity and Its Therapeutic Implications. Cell Rep (2020) 33(10):108487. doi: 10.1016/j.celrep.2020.108487

68. Hasei S, Yamamotoya T, Nakatsu Y, Ohata Y, Itoga S, Nonaka Y, et al. Carnosic Acid and Carnosol Activate AMPK, Suppress Expressions of Gluconeogenic and Lipogenic Genes, and Inhibit Proliferation of Hepg2 Cells. Int J Mol Sci (2021) 22(8):4040. doi: 10.3390/ijms22084040

69. Chen J, Ding C, Chen Y, Hu W, Yu C, Peng C, et al. ACSL4 Reprograms Fatty Acid Metabolism in Hepatocellular Carcinoma via C-Myc/SREBP1 Pathway. Cancer Lett (2021) 502:154-65. doi: 10.1016/j.canlet.2020.12.019

70. Ma APY, Yeung CLS, Tey SK, Mao X, Wong SWK, Ng TH, et al. Suppression of ACADM-Mediated Fatty Acid Oxidation Promotes Hepatocellular
Carcinoma via Aberrant CAV1/SREBP1 Signaling. Cancer Res (2021) 81 (13):3679-92. doi: 10.1158/0008-5472.CAN-20-3944

71. Yu TT, Chang MY, Hsieh YJ, Chang CJ. Suppression of Multiple Processes Relevant to Cancer Progression by Benzyl Isothiocyanate may Result From the Inhibition of Aurora a Kinase Activity. Food Funct (2020) 11(10):9010-9. doi: 10.1039/D0FO01565B

72. Cao X, Bi R, Hao J, Wang S, Huo Y, Demoz RM, et al. A Study on the Protective Effects of Taxifolin on Human Umbilical Vein Endothelial Cells and THP-1 Cells Damaged by Hexavalent Chromium: A Probable Mechanism for Preventing Cardiovascular Disease Induced by Heavy Metals. Food Funct (2020) 11(5):38519. doi: 10.1039/d0fo00567c

73. Roskoski RJr. Properties of FDA-Approved Small Molecule Phosphatidylinositol 3-Kinase Inhibitors Prescribed for the Treatment of Malignancies. Pharmacol Res (2021) 168:105579. doi: 10.1016/j.phrs.2021.105579

74. Roskoski RJr. Properties of FDA-Approved Small Molecule Protein Kinase Inhibitors: A 2021 Update. Pharmacol Res (2021) 165:105463. doi: 10.1016/ j.phrs.2021.105463

75. Eichenmüller M, von Schweinitz D, Kappler R. Betulinic Acid Treatment Promotes Apoptosis in Hepatoblastoma Cells. Int J Oncol (2009) 35(4):873-9. doi: 10.3892/ijo_00000402

76. Hu HX, Gao RR, Gao ZH, Qiao Y, Dong XR, Ding G, et al. Microbial Transformation of Pseudoprotodioscin by Gibberella Fujikuroi. J Asian Nat Prod Res (2018) 20(7):624-32. doi: 10.1080/10286020.2018.1468438

77. Brovkovych V, Izhar Y, Danes JM, Dubrovskyi O, Sakallioglu IT, Morrow LM, et al. Fatostatin Induces Pro- and Anti-Apoptotic Lipid Accumulation in Breast Cancer. Oncogenesis (2018) 7(8):66. doi: 10.1038/s41389-018-0076-0

78. Chen F, Zhong Z, Tan HY, Guo W, Zhang C, Cheng CS, et al. Suppression of Lncrna MALAT1 by Betulinic Acid Inhibits Hepatocellular Carcinoma Progression by Targeting Iaps via MiR-22-3p. Clin Transl Med (2020) 10 (6):e190. doi: 10.1002/ctm2.190

79. Tao R, Wang C, Lu Y, Zhang C, Zhou H, Chen H, et al. Characterization and Cytotoxicity of Polyprenol Lipid and Vitamin E-TPGS Hybrid Nanoparticles for Betulinic Acid and Low-Substituted Hydroxyl Fullerenol in MHCC97H and L02 Cells. Int J Nanomed (2020) 15:2733-49. doi: 10.2147/IJN.S249773

80. Wang W, Wang Y, Liu M, Zhang Y, Yang T, Li D, et al. Betulinic Acid Induces Apoptosis and Suppresses Metastasis in Hepatocellular Carcinoma Cell Lines In Vitro and In Vivo. J Cell Mol Med (2019) 23(1):586-95. doi: 10.1111/jcmm.13964

81. Hwang JT, Park KS, Ryuk JA, Kim HJ, Ko BS. Development of an Oriental Medicine Discrimination Method Through Analysis of Steroidal Saponins in Dioscorea Nipponica Makino and Their Anti-Osteosarcoma Effects. Molecules (2019) 24(22):4022. doi: 10.3390/molecules 24224022

82. Ma X, Zhao T, Yan H, Guo K, Liu Z, Wei L, et al. Fatostatin Reverses Progesterone Resistance by Inhibiting the SREBP1-NF-Kappab Pathway in Endometrial Carcinoma. Cell Death Dis (2021) 12(6):544. doi: 10.1038/s41419-021-03762-0

83. Xue L, Qi H, Zhang H, Ding L, Huang Q, Zhao D, et al. Targeting SREBP-2Regulated Mevalonate Metabolism for Cancer Therapy. Front Oncol (2020) 10:1510. doi: 10.3389/fonc.2020.01510

84. Yao L, Chen S, Li W. Fatostatin Inhibits the Development of Endometrial Carcinoma in Endometrial Carcinoma Cells and a Xenograft Model by Targeting Lipid Metabolism. Arch Biochem Biophys (2020) 684:108327. doi: $10.1016 /$ j.abb.2020.108327

Conflict of Interest: The authors declare that the research was conducted in the absence of any commercial or financial relationships that could be construed as a potential conflict of interest.

Publisher's Note: All claims expressed in this article are solely those of the authors and do not necessarily represent those of their affiliated organizations, or those of the publisher, the editors and the reviewers. Any product that may be evaluated in this article, or claim that may be made by its manufacturer, is not guaranteed or endorsed by the publisher.

Copyright (c) 2021 Zou, Hao and Zhou. This is an open-access article distributed under the terms of the Creative Commons Attribution License (CC BY). The use, distribution or reproduction in other forums is permitted, provided the original author(s) and the copyright owner(s) are credited and that the original publication in this journal is cited, in accordance with accepted academic practice. No use, distribution or reproduction is permitted which does not comply with these terms. 